\title{
Implementation of an innovative teaching project in a Chemical Process Design course at the University of Cantabria, Spain
}

\author{
Berta Galan, Iciar Muñoz and Javier R. Viguri* \\ Green Engineering \& Resources (GER) Research Group. Department of Chemical and \\ Process \& Resources Engineering. ETSIIT, University of Cantabria, Avda. de los Castros s/n, \\ 39005 Santander, Spain \\ *Corresponding author: Javier R. Viguri; E-mail address: vigurij@unican.es
}

\begin{abstract}
This paper shows the planning, the teaching activities and the evaluation of the learning and teaching process implemented in the Chemical Process Design course at the University of Cantabria, Spain. Educational methods to address the knowledge, skills and attitudes that students who complete the course are expected to acquire are proposed and discussed. Undergraduate and graduate engineers' perceptions of the methodology used are evaluated by means of a questionnaire. Results of the teaching activities and the strengths and weaknesses of the proposed case study are discussed in relation to the course characteristics. The findings of the empirical evaluation shows that the excessive time students had to dedicate to the case study project and dealing with limited information are the most negative aspects obtained, whereas an increase in the students' self-confidence and the practical application of the methodology are the most positive aspects. Finally, improvements are discussed in order to extend the application of the methodology to other courses offered as part of the chemical engineering degree.
\end{abstract}

Keywords: process design, learning activities, calculation tools, assessment and evaluation.

\section{Introduction}

The Bologna Process, launched with the Bologna Declaration of 1999, is one of the main voluntary processes at European level. It is currently implemented in the 47 states that define the European Higher Education Area (EHEA, 2013) which is in line with the strategic framework for European Cooperation in Education and Training 2020 (EC, 2009). This process is designed to introduce a system of academic degrees that are easily recognizable and comparable; to promote the mobility of students, teachers and researchers; to ensure high quality teaching; and to incorporate the European dimension into higher education. 
Higher education should be an open process in which students develop intellectual independence and personal self-assuredness alongside disciplinary knowledge and skills. The 2012 EHEA Ministerial Conference in Bucharest reiterated its aim to intensify policy dialogue and cooperation with partners across the world to promote student-centered learning in higher education. This educative approach is characterized by innovative methods of teaching that involve students as active participants in their own learning. During this conference, the future priorities of the EHEA were established as follows: (i) to provide quality higher education for all, (ii) to enhance graduates' employability and (iii) to strengthen mobility to improve learning.

The European Federation of Chemical Engineering (EFCE, 2010) formulated a set of recommendations as program outcomes of the first, second and third cycles in chemical engineering education that are aligned with the Bologna Process. Many bodies in different countries used the EFCE recommendations as a basis for their new chemical engineering curricula and updated these recommendations to include recent developments not only in the Bologna Process, but also in curriculum accreditation guidelines and science and engineering.

In Spain, the first chemical engineering degree was offered in 1992 at a wide range of universities and was 5 years in length, comprising 345 European Credit Transfer and Accumulation System (ECTS) credits (BOE, 1992). Under the Bologna Process, the new degree in chemical engineering is 4 years in length and comprises 240 ECTS credits; this new degree has been implemented in 36 centers and schools at 30 universities between 2009 and 2014. Process Design and Process Simulation \& Optimization courses are included in different modules and subjects with various names at each Spanish university. Figure 1 shows the number of courses related to Process Design, Simulation \& Optimization, Description of Industrial Chemical Processes, and Product Design that are taught as part of the new chemical engineering degree in Spain. The intersections in Figure 1 show the courses that integrate two issues. Process Design and Simulation \& Optimization are typically compulsory courses during the $4^{\text {th }}$ year, although centers provide additional material in elective courses. A high percentage of centers (53\%) add some content related to Process Design and Process Simulation \& Optimization into descriptive Industrial Chemical Processes courses. Only 13\% of centers provide primarily Product Design as a specific elective course or within descriptive courses.

At the University of Cantabria (northern area in Spain) (www.unican.es), the new degree in chemical engineering was first offered in Fall 2010. Currently, the courses Chemical Process Design (6 ECTS) and Simulation and Optimization of Chemical Process (6 ECTS) are offered in the fall and spring semester of the $3^{\text {rd }}$ year, respectively (UC, 2008).

Chemical Process Design constitutes a course that is traditionally considered a "capstone course" for chemical engineering. In this course, students integrate and apply the material 
previously learned and the acquired management skills using specific methods (Biegler et al., 2010; Lewin et al., 2000) that provide them with a real-life engineering design experience. In addition to the student's natural ability and prior preparation, the match between the students' learning profiles and the instructor's teaching style govern the learning process, particularly in these types of courses (Felder and Silverman, 1988; Felder and Spurlin, 2005; Silverstein et al., 2013, Woods, 2011).

The changing context of a new chemical engineering degree and the authors' involvement in the Bologna Process has motivated the authors to introduce an innovative teaching project. In this article, the planning, the instructional activities and the assessment and evaluation of the learning and teaching process implemented in the Chemical Process Design course at the University of Cantabria are shown. Educational methods are proposed to address the knowledge, skills and attitudes that students who complete a course are expected to acquire. In addition, these methods are designed to improve the interest and motivation of the students. The teaching style of the instructor was analyzed simultaneously. The methodology used to align these elements in the course and the assessment results are shown.

\section{Innovation project description (methodology)}

Creating a course to achieve specific outcomes requires effort in planning, instruction, and assessment and evaluation. These domains need to be closely aligned, so that each domain provides feedback to the others so as to provide continuous improvement (CMU, 2013a, b; Felder and Brent, 2003). Figure 2 shows the cyclic methodology followed in the present work to promote the course-specific objectives and the proposed abilities on the chemical engineering degree. Four steps are proposed in this process: improve/redesign the learning methods, implement the improvement measures, monitor the results and evaluate the results to suggest new improvements. Each of the instructional methods proposed is subjected to each of the four cyclic stages, and the information collected during this process is useful for achieving continuous improvement. In this context, the specific learning objectives and the four steps for achieving these objectives may be modified as needed.

The methodology considers the learning objectives of the chemical engineering degree together with the specific objectives of the course to increase the effectiveness of the learning process (Felder, 2012; Felder et al., 2011; Wlodkowski, 1999). Some tactics related to motivation, communication, use of modern information technology and the development of positive attitudes are used to develop the instructional program. Several resources containing useful teaching tips with strategies to teach both more effectively and more efficiently (Bullard, 2010; NCSU, 2013) can be used. 
The instruction applies the proposed instructional activities within the scope of the Chemical Process Design subject. In this context, some initial classes are dedicated to explaining the activities and teaching basic knowledge about the tools the students are going to use (e.g., the sources of information to be used and the software they will apply as calculation tools). The activities are monitored using traditional and internet tools to provide more flexible and efficient communication. Systematic communication among project team students and the teacher is supported by the Blackboard platform and the creation of the course on the Open Course Ware web-based publication (OCW, 2011). Finally, the course is assessed and evaluated to analyze the success of the implemented tactics and to improve and redesign instructional activities that did not achieve the expected results.

\section{Planning: course content and learning objectives}

Table 1 shows the chemical engineering degree abilities that the students will attain, the specific course learning objectives, the educational methods and the assessment tasks proposed for the Chemical Process Design course.

The course introduces students to the methods and background needed to conceptually design continuously operating chemical plants. Particular attention is paid to the use of modern design approaches that are applied in industry as well as to examine problems of current interest. The learning process will involve putting together the previous knowledge of the students and actual learning with a practical and industrial relevance approach. In this context, the ability to work in a group is important, and each student team is assigned to synthesize, design and evaluate an industrial project and to prepare three consecutive design reports and an oral presentation. The main characteristics of the course are related to (i) to its special emphasis on decision-making about the process continuity using evaluation criteria, and (ii) learning to address simplified analysis models, to make guesses and to screen process alternatives (Biegler et al., 1997, 2010;

Seider et al., 2010). The course content is divided into four main blocks: (i) chemical industry factors in process design; (ii) methodological steps involved in process design (i.e., synthesis, analysis and evaluation); (iii) application of methodology to the process subsystems synthesis (e.g., distillation, heat recovery) and (iv) batch processes to manufacture high added value products in flexible plants located close to the market.

\section{Implementation of the instructional activities}

Three specific activities are developed to implement the innovation project, to obtain the learning objectives and to ensure specified abilities to develop and practice skills are attained: 
1. Establish a preliminary design for a chemical process that students should develop during the course using shortcut and simulation tools. Students should prepare three design reports and an oral presentation about the process.

2. Involve industry professionals to increase contact with external industry stakeholders.

3. Establish a teacher-student-design group communication protocol and create a technological dossier about current trends in the chemical industry that are discussed throughout the project.

The proposed learning activities will be implemented in Process Design and Simulation \& Optimization courses. In both courses, the activities are grouped in Classroom activities ( $40 \%$ of the time) (lectures, case studies and teamwork in the computer room), Supervision \& Evaluation activities (15\%) (tutorial and assessment) and Personal Work (45\%) (individual and teamwork).

\section{1.-Preliminary design of a chemical process: production of bioethanol from biomass via hydrolysis.}

The common trend in the teaching of design courses is to design a project based on a real process where students should decide on some design aspects, such as geographic location, the raw material used or the final flowsheet (Biegler et al., 2010; Bullard, et al. 2005). Dutson et al., 1997, presented a literature review on teaching engineering design through project-oriented capstone courses, providing an extensive and useful list of references. More recently, Seider et al., 2010, provided an excellent guidance for teaching product and process design, with Internet links to recommended materials from many sources, including web sites. In this recent work, different case studies were resolved, and design textbooks, monographs, completed design case studies, student contest projects, examples of process design problem statements, design software, PowerPoint lectures, and related materials prepared by design instructors are presented.

The production of bioethanol from lignocellulosic biomass via hydrolysis to meet a specific demand is selected as a course project for the University of Cantabria students. The base case of this project comes from the previous process design cases studies of Martín and Grossmann, 2010 and 2011a, b. The main tasks of the design project are: (i) literature review, process synthesis with raw material choice and gross economic profit analyzing the market variability; (ii) mass and energy balances using shortcut and simulation tools; (iii) economic evaluation using shortcut and simulation tools; and (iv) oral presentation and debate of the designed process. In task (i), students have the ability to choose the raw material that they want to use in their process and the gross economic evaluation should represent the variability of the market, analyzing the influence of the raw material and product prices on the economic profit of the 
plant. In tasks (ii) and (iii), a comparative analysis of the results obtained through both applied tools is performed.

Students are requested to prepare three project reports and an oral presentation that will be useful for showing the main findings during the course and evaluating part of the learning process. The reports include a cover letter, the tasks they have developed, the applied methodology and the main results obtained. The final oral presentation of the whole project, based on PowerPoint, includes a presentation of the teamwork, key indicators of the design and major remarks and recommendations.

When using projects to teach engineering design, students frequently encounter issues with project management and the project management tools that can be used to solve these issues (Moor and Drake, 2001). Thus, an initial milestone schedule is implemented in the process design course, as well as project review meetings at the end of each proposed step, design reports that document each design task as the project progresses and the design of an active protocol of communication among design team members and the teacher.

\subsubsection{First Step: Report 1 on the development of alternatives}

The major issue in this report is the generation of alternatives and the selection of the flowsheet configuration because a significant number of process alternatives exist. A literature review is performed to understand the wide range of raw materials and the associated process alternatives that exist for designing each step of the bioethanol production process. Figure 3 shows a superstructure for a bioethanol production process via hydrolysis; the raw materials include spent sulfite liquor from a local company that manufactures dissolved pulp.

Students must generate alternatives, create their own superstructure and discuss the alternatives presented to decide on the path they are going to follow to produce bioethanol. Once the decision is made, they must draw a preliminary process flowsheet that describes the major qualitative aspects of the process. The flowsheet should indicate the equipment they expect to use in their process. Three flow diagrams embedded within the superstructure (Figure 3) have been resolved completely. In the first diagram (named the Barley-1 process), barley is used as the raw material, and the process that is performed includes grinding and AFEX pretreatment, enzymatic hydrolysis, SHF Fermentation, and a final pervaporation as dehydration step. In the second alternative (named as Barley-2 process), barley is also used, and the process followed is hydrothermal pretreatment, SSF and a final extractive distillation as dehydration step. Finally, spent liquor is used as the raw material (named as Spent-Liquor process), with an acid pretreatment and hydrolysis, followed by SHF fermentation and extractive distillation as the final step. 
A gross economic evaluation for the process based on maximum potential benefits is requested to determine the process viability. The objective of this task is to provide information about the total sales from the product; the investment on raw materials acquisition; and the shipping cost, which includes the storage of materials and transportation cost.

The selection of raw material and fluctuations in the market price of raw material acquisition and the bioethanol selling price allow the students to observe the high variability in the economic benefits obtained with the selected production flowsheet. Figure 4 shows the economic analysis for the three alternatives (Barley-1, Barley-2 and Spent-Liquor), establishing a combination of bioethanol and raw material prices, which provides the process with zero profit (Straight lines). In Figure 4, some referenced bioethanol and raw material prices (squares) and the cost of bioethanol production using different raw materials (see the table within the figure) are shown.

Next, students will discuss the bioethanol and raw material prices of their selected process. In some cases, it will be necessary to establish bioethanol prices that are higher than the current market value or apply for a subsidy from the government if a positive profit is requested. Currently, subsidies do not exist for bioethanol production in Spain. However, there are some economic grants from particular projects with the aim of encouraging its production (APPA, 2005). The European Commission recently established a new directive to promote the use of second generation biofuels. The proposal does not take a position on the actual need for financial support for biofuels before 2020. However, the Commission believes that after 2020, biofuels that do not lead to substantial greenhouse gas savings (when emissions from indirect land-use change are included) and that are produced from crops that are used for food and feed should not be subsidized (EC, 2012). This topic is a good opportunity to show students teamwork, the concept of sustainable design and to implement active learning tactics such as "thinking-aloud pair problem solving" (Felder and Brent, 2009).

\subsubsection{Second Step: Report 2 on the analysis of the selected flowsheet.}

This report involves the elaboration and analysis of the final flowsheet that the students follow during their process. The flowsheet must present a detailed process using the correct symbols for the equipment and numbering each stream. Figure 5 shows a proposed flowsheet for the Barley-1 bioethanol production process.

Mass and energy balances are required for the overall plant and the individual units. The objective of the heat and material balances is to obtain five magnitudes for every stream on the flowsheet: temperature, pressure, composition, total flow rate, and phase condition. All the flow 
rates, heat duties and works are reported on the basis of 100 gmol glucose/s leaving the hydrolysis tank.

As mentioned previously, encouraging students to simulate a chemical process using different calculation tools for the same design is one of the course objectives. It is desirable that students, with their understanding of the basic concepts, will be able to validate the results and test the accuracy of the tools used. It is additionally important for students to understand the strengths, weaknesses and limitations of the tools used for solving problems. Thus, shortcut (Microsoft Excel software) and simulation (Aspen Plus Software) tools are proposed to perform this task. Shortcut tools can generate more imprecise calculations, but they force students to learn the process mechanism. Simulation programs generate more precise results, but they do not help student understanding regarding how these tools operate.

To develop the mass and energy balances in Microsoft Excel, students should use Biegler et al., 1997, as their main reference. This study provides some detailed information about the major assumptions needed to solve the balances. In addition, students can find the mass and energy balance equations for the equipment used in the process design. The works of Douglas, 1988, Peters et al., 2002, Seider et al., 2010, and Sinnot and Towler, 2009, are additional textbooks that are particularly recommended to students. Aspen Plus provides a set of different equipment that the students can use to solve their process. Depending on the operation that must be simulated, different units can be used. To solve the balances with this tool, it is only necessary to complete the equipment description with the specific information that this software requires. On some occasions, it is needed to impute some data with the aim of running the simulation; then, the assumption should be analyzed to decide whether the obtained results match the expected ones.

The Aspen library collects information on numerous pieces of equipment, but it does not include some units (e.g., pervaporation, conventional evaporation, heated soaking vessel or distillation columns with heat integration), so different flow diagrams that have the same function as the tool used can be utilized. In the present case study, Barley-1, the main differences between the shortcut and Aspen flowsheets take place at two stages: at the final step of fermentation, where a separation system is required to purify the stream and remove gases and biomass components, and at the dehydration step, where the separation process must be modeled. As shown in the splitting of Figure 5, the equipment used at the final step of the fermentation is a T-screen (i) in the shortcut calculations and a flash followed by a conventional separator (ii) in the simulated calculations. In addition, the process design establishes the necessity of using a dehydration system to separate a large amount of water from the product mixture. At the first step of this process, a multi-effect distillation column with a heat integration system (iii) and two parallel distillation columns (iv) are used for shortcut 
calculations and simulated calculations, respectively. Finally, a dehydration unit is required to separate ethanol and water at the end of the process. Using shortcut tools, a pervaporation step (v) can be used for this purpose; however, Aspen Plus does not include this operation in the library that is available to students; therefore, for the simulation process, a commercial separator (vi) replaces it.

The particular combination of operation units selected can cause differences in the results of the characteristics of outlet streams. One goal of this assignment is to compare the results obtained with both calculation tools. In the case of the Barley-1 flowsheet, an outlet stream, which consists of $284.67 \mathrm{~mol} / \mathrm{s}$ of bioethanol and $0.65 \mathrm{~mol} / \mathrm{s}$ of water, at a temperature of $298^{\circ} \mathrm{C}$ and a pressure of $101 \mathrm{kPa}$ of, is obtained using the shortcut tools. The outlet stream obtained by simulation tools has approximately $281.14 \mathrm{~mol} / \mathrm{s}$ of bioethanol at a temperature of $298^{\circ} \mathrm{C}$ of and a pressure of $101 \mathrm{kPa}$. This stream does not have water because it was removed completely by the dehydration system. Students could complete this comparative analysis by identifying the differences in the magnitudes obtained to the process streams in the steps of pretreatment, hydrolysis and fermentation. A comparative inter-groups and intra-groups analysis of the outlet streams' characteristics and of the yield of the process obtained by shortcuts and simulation tools is proposed at the end of this second student report. The process simulations developed in this step would be used in the Simulation \& Optimization course as case studies.

\subsubsection{Third Step: Report 3 on the economic evaluation of the selected flowsheet.}

To evaluate the process, an economic analysis should be performed. The objective of this report is to estimate the capital and operating cost derived from equipment sizing specifications, utility and labor requirements, product and raw material rates and other similar information. The application of shortcut methods such as Microsoft Excel, which is commonly used in the industry, and Aspen Process Economic Analyzer, which allows estimating process capital and operational costs, are proposed to be used by students for the economic evaluation.

The economic evaluation using shortcut tools is performed following Guthrie's modular method (Biegler et al., 1997). The first step of the economic evaluation is to determine the equipment sizing specifications by calculating all the physical attributes that allow a unique cost of each process unit. A number of assumptions related to construction materials, design, efficiencies and design rules of thumb must be taken into account by the students (Branan, 2005; Peters et al., 2002; Ulrich and Vasudevan, 2004).

One goal of this assignment is to compare the results obtained with both calculation tools. Figure 6 shows the breakdown of capital costs and manufacturing costs obtained by Aspen (Figure 6a) and shortcut tools (Figure 6b) for the Barley-1 process design to obtain bioethanol. 
The economic results indicate a total project capital cost of approximately $2.62 \mathrm{E}+8 €$ and was very similar using both calculation tools, with a desired rate of return of $20 \%$ per year and a project life of 20 years. The results obtained with both proposed calculation tools demonstrate that the major costs come from the project capital costs, which include the onsite cost, manufacturing capital, contingencies and inventory costs. In contrast, utility costs and labor and maintenance costs provide minor contributions to the total cost of the process, depending on the selected flowsheet (Figure 5). As explained previously, the use of more sophisticated process units, with higher utility requirements, is only possible when shortcut tools are used; in contrast, during the simulation with the Aspen Process Economic Analyzer, some assumptions and simplifications are made that reduce the estimate for utility costs.

Figure 7 shows the breakdown of the equipment capital cost estimation generated with the Aspen Process Economic Analyzer (Figure 7a) and Microsoft Excel tools (Figure 7b). Both calculation tools identify the reactors as the units with the higher contribution, accounting for more than $50 \%$ of the total estimated equipment capital costs. This high cost is due to the high volumes required to perform the fermentation and hydrolysis reactions. In contrast, the distillation columns are the equipment that generates the lowest cost. Thus, these calculation tools offer similar results for the economic evaluation of this project.

Based on the mass and energy balances in Report 2, a complete calculation of the size and cost of every major piece of equipment in the selected flowsheet is made. With this data, together with the basic economic parameters provided by the instructor, the student workgroup are required to estimate profitability measures. Measures such as the return of investment (ROI), payback period (PBP), net present value (NPV) and investor's rate of return (IRR) would be useful before a final decision is made on whether to proceed with a new venture. This project step will require that students perform a sensitivity analysis on key parameters, including market issues from Report 1, and offer a recommendation on the economic viability of the process. A comparative inter-groups and intra-groups analysis of the economic evaluation obtained by shortcut and simulation tools is proposed at the end of this third report.

\subsection{Involvement of industry professionals.}

One of the major influences on the development of capstone design courses has come from the needs of industry. Industrial involvement in capstone design courses includes different tactics (Dutson et al. 1997). The involvement of industry professionals is proposed in the present project. Teaching specific seminars that are related to real industrial design problems and assisting in the evaluation of team projects are proposed as learning methods during the Chemical Process Design course at the University of Cantabria. The teaching activity is related to the application of some aspects of preliminary process design for companies, with the use of 
simulation and optimization tools applied by the industry. Thus, during the Fall 2012 semester, two conferences taught by chemical industry professionals were developed: (i) Process design in the cellulose pulp sector (Sniace S.A. Company) and (ii) Application of conceptual engineering to energy generation processes (Iberdrola S.A. Company).

The development of this activity entails defining the scope and content as well as scheduling the conferences and determining the proper perspective that the speakers should establish. The objective is to allow students to become familiar with industrial reality of the subjects involved in the development of the course Chemical Process Design. In addition, some suitable documentation should be facilitated in advance for the students, so they can easily follow the lecture. A final exchange and discussion of ideas, opinions and curiosities and the planning of questions about the analyzed theme was promoted in an informal, flexible and interactive environment. Interaction with engineers from the industry helps students build self-confidence and interpersonal skills prior to entering the work force (Dutson et al. 1997). This learning method allows students to understand the real implications of the competences and abilities we expect them to achieve during the course and the decision-making strategies applied by industrial companies.

Including seminars by professionals from industry is a good opportunity to highlight the importance of product design in the field of chemical engineering (Cussler and Moggridge, 2011; IChemE, 2013; Wei, 2007). Integrated chemical product-process design is one of the more established integrative practices, mainly for performance products in both industry (Martín and Martinez, 2013; Seider et al., 2009) and academia (Seider and Widadgo, 2012).

\subsection{Protocol for communication among the teacher, students and design group.}

\section{Technological dossier about current trends and events in the chemical industry.}

Developing a protocol of communication is necessary to supply students and design groups with some systematic procedures. This task proposes the implementation of communication tools as a suitable system for use in any of the steps of the cyclic methodology followed to obtain the course-specific objectives (Figure 2). The communication protocol used in this course mainly consists of e-mail, the University of Cantabria's Blackboard platform and the course implemented in Open Course Ware. These systems allow correct monitoring of the course because all the information taught in the class is posted on these platforms and is available to be downloaded. Using these tools allows students to find out about dates, homework, comments on their reports, lecture slides, additional information and some subject-related comments. In addition, problems can be addressed by answering questions, and doubts are removed using this system. 
The elaboration of a current technological dossier is important for creating contact between students and real technological aspects and for considering social, ethical and market aspects. Learners are advised to do intensive research on process technology, social implications and market economy related to bioethanol production using chemical engineering journals and magazines of general dissemination. In this way, they are advised to review the press and collect all news stories they consider related to these aspects. Students are also provided with some information about specific internet pages they can use (CheEng, 2013; IHS-GlobalSpec, 2013; TEMA, 2013). On these websites, they can find information about innovation in chemical processes, business and economics, and some instructions and specifications about the equipment used in the chemical industry. Finally, searching some common websites and journals is recommended to obtain information related to the project and the product case study. All information found in the search is collected and discussed in class with regard for understanding professional and ethical responsibility and for promoting critical thinking skills for the decisions required during the preliminary project design.

Certain strategies such as institutional actions (AiChE, 2011; UC, 2013), staff mobility of authors on international sabbaticals (Galán, 2010; Viguri, 2010), the involvement of industries that operate globally (industrial seminars) and the use of the English language in lectures and project statements (OCW, 2011) are used to apply internationalization during the course.

\section{5. - Assessment \& Evaluation of learning and teaching}

Assessment of learning should reveal the level of knowledge that the students have acquired with regards to what the teacher wants them to learn, whereas instruction ensures that they learn it. Learning must be assessed through performance: how students are able to apply their learning. Different strategies for assessing students' learning (CMU, 2013a, b; Felder et al., 2000) can involve assessments that are formal or informal, high- or low- stakes, anonymous or public, individual or collective. Different strategies such as individual exams; design project reports, including cover letters and reporting recommendations; oral presentations including student self-evaluation; and regular self-assessment of workgroups functioning are used in the Chemical Process Design course (Figure 8).

Several methods are used to assess the instructional quality (Felder et al., 2000; Felder and Brent, 2004). At the University of Cantabria, the main components of instructional quality assessment (Figure 8) are student rating forms issued at the end of the course, which cover items related to course teaching, together with the self-assessment by the instructor. The rating form proposed by the University of Cantabria consists of a survey with 17 items, scored on a scale of 0 to 5 points, to assess the course and the lecturer. The average mark obtained after the 
introduction of the previously described innovation tactics in 2012 is 3.5 points, which is a rise of approximately 0.6 points above the median of the last five years (a global improvement of $20 \%$ ). This evaluation is completed with a self-evaluation report on the teaching activity as a process of reflection on the educational activity.

Innovative teaching introduced by the instructional activities described in this paper is assessed by undergraduate and graduate engineering students (Figure 8) with a survey of open-ended questions, leaving plenty of space for the responses and comments. A questionnaire given in the Appendix I was developed with four sections to gather perceptions of the proposed methodology. The survey to obtain empirical data has four sections: Section I evaluates the activities and materials proposed as a learning method (i.e., bioethanol production process design project, industrial conferences, technological dossier and protocol for communication), as well as different aspects of the followed methodology (i.e., teamwork, time spent in classes, etc.). Section II of the survey are questions related to the skill gained by the students. By section III, students are asked about some generic and specific items about the case of study. Finally, section IV is made up of questions about the course and its academic integration. Both undergraduate and graduate engineering students, with the aim of analysing the progress of the implantation of the course, have completed out the survey.

Surveys were answered by 35 undergraduates and 14 graduated engineering students in February 2015. At that time, the proposed course methodology had been applied for two years. The results of the surveys for questions in Section I, related to the course methodology, are shown in figures 9-10.

In figure 9, it is shown that for engineering graduate students, the seminars by industrial professionals are considered the most positive activity with a mark of 4.66 , whereas for undergraduate students, the most beneficial item is the visit to an industrial plant. Having real contact with industry and the perception that teaching strategies were successfully applied, are positively evaluated by both undergraduate and graduate students. The part of the course which graduate engineers considers less useful is the bioethanol case study, rating it 1.53 compared to 2.82 that the Open Course Ware obtains, which receives the worst score from students. The fact that these parts of the course had too much theoretical content and were not very dynamic meant they were of little interest to undergraduate and graduate students.

Assessment of other aspects of the methodology application (Figure 10) shows that teamwork is given the highest score (3.78) by graduate engineers, whereas new concepts presented on the course received the top score (3.6) from undergraduates. On the other hand, the amount of time spent on the bioethanol case study is the item which is most criticized by graduate engineers 
whilst undergraduates found the most complex item to be the comprehensive coverage (2.91). This fact implies the need to analyse the bioethanol project with the aim of reducing the time required for its development, and going over the key concepts for students to understand the subject completely.

Furthermore, it is shown that all students rate both the structure and the evaluation system of the course in a positive way in comparison with other subjects. This is a good indicator to show that the design of this course has dealt adequately with the deficiencies of other subjects. In a nutshell, students feel that the methodology used for these subjects is better than those followed on other subjects.

As far as student learning is concerned, students positively rate (3.31) the fact that what was asked in the exams corresponded to what they expected. Besides, students consider that they were knowledgeable about what they had to learn on this subject, though graduate engineers consider that they were not sufficiently aware of everything they had to learn, showing in this way a progress in the application of the proposed methodology. In spite of undergraduate and graduate students showing different assessment in some of the studied items, both groups agree with the fact that they would like to see this methodology implanted in other subjects (3.17 for undergraduate students and 3.57 for graduate engineers).

According to the results of Section II, which is related to the skills and abilities that students acquired during the course, both undergraduate and graduate students have positively evaluated the methodology used. Furthermore, they feel that it has contributed to them improving their knowledge. They also consider that their ability to solve problems has been developed much more than on other courses because of the specific approach used on this course. The limited amount of information students were provided with to develop the bioethanol project got the worst rating in the case of graduate engineers. For undergraduate students, this aspect is the third most negative, with the use of seminars by industry professionals obtaining the worst score and the second most negative aspect is that they consider that much of what they have learnt remains unconnected, i.e. they cannot link it to a broader context. The acquired technical knowledge is probably too specific and related to the case study. Some students also mentioned that before practical classes, they had problems to understanding the applicability of the theory. However, the fact that they had applied the theoretical concepts from the lectures to develop design project helped them to apply the topic to a general background.

The average score of 3.5 and 3.6 for graduate engineers and undergraduate students respectively, obtained in Section II of the survey, seems to suggest that considerable support is given to the fact that design activities are beneficial to help students to understand how they can apply the theory in case studies. Finally, it is extremely positive that undergraduate students as 
well as graduate engineers think that the course has been interesting (3.46) and they have learnt certain aspects that would have been impossible to learn using a traditional approach (4.14).

Figure 11 shows the assessment of the positive and negative aspects of the bioethanol case study (Section III of the survey). Items rated positively by students (Figure 11 a) were the practical application of the case study with a support of 20.39\%, student learning (15.16\%) and increased knowledge (14.47\%). In the case of graduate engineers (Figure $11 \mathrm{~b}$ ), the most important aspects of the project were the practical application again with a support of $18.34 \%$, followed student learning with $16.67 \%$ and thinking for themselves with $16.67 \%$..

The most negative aspect for both groups of surveyed students was the excessive time they had to dedicate to the project (which is a worldwide complaint among students of project-based learning (Gavin, 2014; Palmer and Hall, 2011)) followed by the difficulty of developing the project due to the lack of previous information about the process.

Furthermore, a considerable problem was the quality of teamwork, which was related to how some members of the group were not sufficiently committed to the tasks they had to do. The individual evaluation of each member of the group, as well as the development of some early strategies to detect problems or dysfunctions in the teamwork, will be new aspects to be applied during the next academic year. When asked how useful the bioethanol case study is to understand the world of industry, results indicate agreement with the fact that the bioethanol case study helped them to improve the knowledge they had about industry with an average mark of 4.06. Furthermore, a rating of 3.75 was given to how this course allows students to generate new abilities and knowledge in the background of process design using concepts acquired in the lectures.

In Section IV, related to general questions about the subject and its academic integration, graduate engineers rated their knowledge in process design with 3.16 before the course and 3.85 after it. In the case of undergraduate students, this variation is from 1.78 to 3.78 . This shows how efficient the methodology is in order to improve their knowledge in the topic, which is supported with a mark of 3.78 from graduate engineers and with 4 from undergraduate students. Besides, this fact is confirmed as when asked whether they would recommend the subject to future students, an average mark of 4.01 was given. Therefore, the majority of students are satisfied with the subject.

Regarding the question "Interest in design process" a mark of 3.69 was given by undergraduate students and 3.64 by graduate engineers. When asked whether they see their future linked to process design, the value obtained is 3.80 and 3.71 respectively. This suggests that a vast number of them are interested in developing their career in this background. This determines the 
fact that students assess the possibility of studying a subject with a similar topic with a score of 3.35 .

From a general point of view, students feel that the course plays an important role in higher education (4.01) and they consider that its applicability to Chemical Engineering is very good (4.50). Furthermore, they consider that process design adds value to their global learning.

\section{Conclusions}

This paper summarizes the work developed at the University Cantabria, Spain, to improve the concerns of the student related to the Chemical Process Design course. The methodology to create the course and the planning approach, implementation of the instructional activities and the obtained results of the assessment $\&$ evaluation are discussed in the context of the new chemical engineering degree.

The learning objectives of the chemical engineering degree, together with the specific objectives of the chemical process design subject, are formulated. Innovative learning activities proposed to reinforce objectives and prepare students for assessments are (i) establish a preliminary design for a chemical process to be developed in the course using shortcut and simulation tools, (ii) involve industry professionals, and (iii) establish a communication protocol between design team students and the teacher and create a technological dossier about current industrial trends.

The learning methods proposed have been evaluated by asking undergraduate students and graduate engineer to take part in a survey. The results indicate a high level of objective achievement but it was felt that longer was dedicated to self-study time than had been expected. Students prefer more dynamic teaching activities, which have direct contact with the world of industry, such as the chemical plant visit and seminars by industrial professionals as opposed to subjects with a higher theoretical content like case studies and Open Course Ware information. These preferences are in accordance with the course characteristics, where working with limited information, to address open-ended problems and the importance of the reasoning process in decision-making are more important goals than obtaining accurate results. The main strengths regarding the proposed bioethanol case study are its practical application and the opportunity to learn from classmates, whereas the main weaknesses detected by students are the amount of time required for the development of the case study, the perceived level of difficulty and carrying out group work. 
It was found that undergraduate students were more in favor of visits to industrial plants and working with the bioethanol case study than the graduate engineers, who favored the seminars given by industrial professionals. In relation to the preliminary project design, thinking by yourself, communication skills and quality of the teamwork are the aspects with higher valuation differences between undergraduate students and graduate engineers. The results obtained may be due to the fact that graduate engineers are more mature and they value individual learning aspects directly related to the world of industry to a greater degree than undergraduate students do.

The average mark obtained in the official survey of the University of Cantabria (17 items) after the introduction of the previously described innovation tactics in 2012 is 3.5 out of 5, which is a global improvement of $20 \%$ with respect to the students that did not follow this methodology in previous years. However, in the observations it was considered necessary to modify this course to improve: (i) the evaluation system for each member of the team in the project; (ii) the detection and solution of problems in the teamwork activities; (iii) the amount of time allotted to the project. Suggested changes include more concise scheduling of activities during the course, flexibility to change learning activities depending on the continuous assessment, continuous monitoring during the teamwork stage, increasing the involvement of the industry professionals, more tutorials for project development, and improving the student's perception of the course by explaining the innovation activities that have been developed.

The results shown in this paper would be useful for the future implementation of project based learning courses in the chemical engineering degree; however, it is necessary to design coordinate actions with other subjects related to design (e.g., Product Design; Business Administration and Management courses) and to the life cycle of a process design, including basic subjects studied on the chemical engineering degree (e.g., Chemistry and Thermodynamics \& Heat Transfer courses) and industry-oriented subjects (e.g., Project Management and Mass \& Energy Balances courses).

\section{Acknowledgment}

The authors are indebted to Professor Ignacio Grossmann for invaluable comments of an early draft of this paper. Berta Galan and Javier Viguri was funded by the Spanish Ministry of Education by means of an fellowship of mobility of professors and researchers in foreign centers of higher education and research (Chemical Engineering Department, Carnegie Mellon University, USA) Ref. PR2009-0212 and Ref. PR2009-045. This work was partially supported with the financial help of the University of Cantabria, $1^{\text {st }}$ and $2^{\text {nd }}$ Teaching Innovation Programs 2011-2012, 2013-2014, Projects Innodesign 1 and 2. 


\section{References}

AiChE 2011. American Institute of Chemical Engineers. Universidad de Cantabria Student Chapter. Santander: AiChE. Available at: http://www.aiche.org/community/students/chapters/universidad-de-cantabria-student-chapter (as for July 2013).

APPA, 2005. Association of renewable energies producers. A strategy of biofuels for Spain 2005-2010. Adaptation to Directive 2003/30/CE objectives. Spain: APPA. Available at: http://www.appa.es/descargas/Estrategia_Biocarbur_APPA.pdf (as of May, 2013).

Biegler, L.T., Grossmann, I.E. and Westerberg, A.W. 1997. Systematic methods of Chemical Process Design. New Jersey: Prentice Hall. ISBN: 0-13-492422-3.

Biegler, L.T., Grossmann, I.E. and Westerberg, A.W. 2010. Issues and Trends in the Teaching of Process and Product Design. AIChE Journal. 56; 5: 1120-1125.

BOE 1992. Official Newsletter of the State. RD 923/1992, of 17 July 1992, by establishing the official university degree Chemical Engineer and the approval of the general directives of the curriculum leading to the award of that (BOE, n² 206, 27 August 1992).

Branan C. 2005. Rules of Thumbs for Chemical Engineers: A Manual of Quick, Accurate Solutions to Everyday Process Engineering Problems. $4^{\text {th }}$ Ed. Elsevier. ISBN: 978-0-75067856-8.

Bullard, L. G., Niehues, P.K., Peretti, S.W. and White, S.H. 2005. Web-based delivery of ChE design projects. Chemical Engineering Education. 39; 3: 194-199.

Bullard, L.G. 2010. Tips on Efficient, Effective, Student-Centered Teaching. Chemical Engineering Education. 44; 4. Fall 2010.

CheEng 2013. Chemical Engineering. New York: CheEng. Available at: http://www.che.com/ (as for May 2013).

CMU 2013a. Carnegie Mellon University. In: Eberly Centre. Teaching Excellence \& Educational Innovation: Assess Teaching \& Learning. Basics. Pittsburgh: CMU. Available at: http://www.cmu.edu/teaching/assessment/basics/alignment.html (as for June 2013).

CMU 2013b. Carnegie Mellon University. In: Eberly Centre Teaching Excellence \& Educational Innovation: Assess Teaching \& Learning. Assessing learning. Pittsburgh: CMU. 
Available at: http://www.cmu.edu/teaching/assessment/assesslearning/index.html (as for June 2013).

Cussler, E.L. and Moggridge, G.D. 2011. Chemical Product Design. $2^{\text {nd }}$ Ed. Cambridge Series in Chemical Engineering. ISBN: 978-0521796330.

Douglas J. 1988. Conceptual Design of Chemical Processes. New York: McGraw-Hill. ISBN: 0-07-017762-7.

Dutson, A.J., Tood, R.H., Spencer, P.M. and Carl, D. 1997. A Review of Literature on Teaching Engineering Design through Project- Oriented Capstone Courses, Journal of Engineering Education. January 1997: 17-28.

EC 2009. European Commission. Council Conclusions of 12 May 2009 on a strategic framework for European cooperation in education and training (ET 2020). Official Journal of the European Union._2009/C119/02.

EC 2012. European Commission. Proposal for a Directive of the European Parliament and of the Council amending Directive 98/70/EC relating to the quality of petrol and diesel fuels and amending Directive 2009/28/EC on the promotion of the use of energy from renewable sources. Brussels (BE): EC. COM (2012) 595 final.

EFCE 2010. European Federation of Chemical Engineering. EFCE Bologna Recommendations: Recommendations for Chemical Engineering Education in a Bologna Three Cycle Degree System. $\quad 2^{\text {nd }}$ revised ed., 2010. Germany: EFCE. Available at: http://www.efce.info/efce_media/Downloads/2010_EFCE_Bologna_Recommendations_final.p df (as for May 2013)

EHEA 2013. European Higher Education Area. Romania: EHEA. Available at: http://www.ehea.info/ (as for May 2013).

Felder, R.M. 2012. New STEM Faculty Support: Why Aren't We Providing It? Journal of STEM Education. 13; 5. October-December 2012.

Felder, R.M. and Brent, R. 2003. Designing and teaching courses to satisfy the ABET engineering criteria. Journal of Engineering Education. 92; 1: 7-25.

Felder, R.M. and Brent, R. 2009. Active learning: an introduction. ASQ Higher Education Brief. 2; 4. August 2009. 
Felder, R.M. and Brent, R. 2004. How to evaluate teaching. Chemical Engineering Education. 38; 3: 200-202. Felder, R.M. and Silverman, L.K. 1988. Learning and teaching styles in engineering education. Engineering Education. 78; 7: 674-681.

Felder, R.M. and Spurlin, J. 2005. Applications, reliability and the validity of the Index of Learning Styles. International Journal of Engineering Education. 21; 1: 103-112.

Felder, R.M., Rugarcia, A. and Stice, J.E. 2000. The future of engineering education v. assessing teaching effectiveness and educational scholarship. Chemical Engineering Education. 34; 3: 198-207.

Felder, R.M., Brent, R. and Prince, M.J. 2011. Engineering instructional development: Programs, best practices, and recommendations. Journal of Engineering Education. 100; 1: 89122.

Galán, B. 2010, Senior Mobility Spanish Program PR2009-045. Chemical Engineering Department. Carnegie Mellon University (CMU). Pittsburgh, PA, USA. 01.01.2010 27.09.2010. Available at: http://www.mecd.gob.es/educacion-mecd/areaseducacion/universidades/convocatorias.html (as for July 2013).

Gavin, K. 2014. Case study of a project-based learning course in civil engineering design. European Journal of Engineering Education. 36; 6:547-558.

IChemE 2013. Institution of Chemical Engineers. IChemE's Education Special Interest Group. Available at: $\quad$ http://www.icheme.org/communities/special-interestgroups/education/about\%20us.aspx (as for July 3013).

IHS-GlobalSpec. 2013. IHS GlobalSpec Products and services catalogue. New York: IHSGlobalSpec. Available at: http://www.globalspec.com/ (as for May 2013).

Lechón, Y., Cabal, H., Lago, C., De la Rúa, C., Sáez, R.M. and Fernández, M. 2003. Analysis of life cycle analysis of alternatives biofuels for transport. (Análisis del ciclo de vida de biocombustibles alternativos para el transporte). Ed. Centro de Publicaciones Secretaria General Técnica. Ministerio de Medio Ambiente. ISBN: 84-8320-312-X. 2005.

Lewin, D.R., Seider, W.D. and Seader, J.D. 2000. An integrated approach to process design instruction. Computers and Chemical Engineering. 24; 2-7:1369-1374.

Martín, M. and Grossmann, I.E. 2010. Conceptual Design of Second Generation Bioethanol Production via Gasification of Lignocellulosic Biomass. CACHE Process Design Case Studies. 
Martín, M. and Grossmann, I.E. 2011a.Conceptual Design of the Supply Chain and Production Facility of Lignocellulosic Bioethanol via Hydrolysis. CACHE Process Design Case Studies.

Martín, M. and Grossmann, I.E. 2011b. Energy Optimization of Bioethanol Production via Hydrolysis of Switchgrass. AIChE Journal. 58; 5: 1538-1549.

Martín, M. and Martínez, A. 2013. A methodology for simultaneous product and process design in the customer products industry: The case study of the laundry business. Computer Aided Chemical Engineering. 32; 715-720.

Moor, S.S. and Drake, B.D. 2001. Addressing Common Problems in Engineering Design Projects: A Project Management Approach, Journal of Engineering Education. 90; 3: 389-395.

NCSU, 2013. North Carolina State University. In: Richard Felder's education-related publications. $\quad$ Raleigh: NCSU. Available at: http://www4.ncsu.edu/unity/lockers/users/f/felder/public/Papers/Education_Papers.html (as for July 2013).

OCW 2011. Open Course Ware. Chemical Process Design Course. Cantabria: OCW. Available at: http://ocw.unican.es/ensenanzas-tecnicas/procesos-quimicos-de-fabricacion (as for May 2013).

Ortíz, S. 2003. Looking for alternative fuels: the bioethanol. (Buscando combustibles alternativos: el bioetanol). Anales de mecánica y electricidad. 80; 4: 46-53.

Palmer, S. and Hall, W. 2011. An evaluation of a project-based learning initiative in engineering education. European Journal of Engineering Education. 36; 4: 357-365.

Peters, M.S., Timmerhause, K.D. and West, R. 2002. Plant design and economics for chemical engineering. $5^{\text {th }}$ Ed. New York: McGraw-Hill. ISBN: 0-07-1198772-5.

Sánchez-Macías, Rodríguez, F., Calero, P. and Díaz, F.J. 2005. Agro-industrial development of biofuels in Castilla y León. (Desarrollo agroindustrial de biocombustibles en Castilla y León). Premio Colección de Estudios del Consejo Económico y Social de Castilla y León.

Seider, W.D., Widagdo, S., Seader, J.D. and Lewin, D.R. 2009. Perspectives on chemical product and process design. Computers and Chemical Engineering. 33; 930-935.

Seider, W.D., Seader, J.D., Lewin, D.R. and Widagdo, S. 2010. Product and Process Design Principles: synthesis, analysis and evaluation. $3^{\text {rd }}$ Ed. New York: John Wiley \& Sons. ISBN: 0470048956. 
Seider, W.D. and Widadgo, S. 2012. Teaching chemical engineering product design. Current in Chemical Engineering. 1; 472-475.

Silverstein, D.L., Bullard L.G., Seider, W.D. and Vigeant, M.A. 2013. In: American Society for Engineering Education. How We Teach: Capstone Design. Kentucky: ASEE. Available at: http://www.asee.org/public/conferences/20/papers/7241/view (As for June 2013).

Sinnot, R. and Towler, G. 2009. Chemical Engineering Design. $5^{\text {th }}$ Ed. Burlington, MA: Elsevier/Butterworth-Heinemann. ISBN: 978-0-7506-8551-1.

TEMA 2013. The Tubular Exchanger Manufacturers Association, Inc. 2013. New York: TEMA. Available at: http://www.tema.org (as for May 2013).

UC 2008. University of Cantabria. Memory for verification request official titles. Proposal degree in Chemical Engineering (Memoria para la solicitud de verificación de títulos oficiales. Propuesta de título de grado en Ingeniería Química). Cantabria: UC. Available at: http://www.unican.es/of/DOT/MET-G-QUIMICA.pdf (as for June 2013).

UC 2013. University of Cantabria. Agreements and Networks. Cantabria: UC. Available at: http://www.unican.es/WebUC/Unidades/relinteng/agreements/ (as for July 2013).

Ulrich, G. and Vasudevan, P. 2004. A Guide to Chemical Engineering Process Design and Economics. $2^{\text {nd }}$ Ed. New York: John Wiley \& Sons. ISBN: 0-471-08276-7.

Viguri, J. 2010. Senior Mobility Spanish Program PR2009-0212. Chemical Engineering Department. Carnegie Mellon University (CMU). Pittsburgh, PA, USA. 01.01.2010 27.09.2010. Available at: http://www.mecd.gob.es/educacion-mecd/areaseducacion/universidades/convocatorias.html (as for July 3013).

Wei, J. 2007. Product Engineering: Molecular Structure and Properties. Oxford University Press, USA. ISBN: 978-0195159172.

Wlodkowski, R.J. 1999. Enhancing Adult Motivation to Learn: A Comprehensive Guide for Teaching All Adults. $2^{\text {nd }}$ ed. New York: John Wiley and Sons.

Woods, D. 2011. Motivating and Rewarding Universities Teachers to Improve Students Learning. A Guide for Faculty and Administrators. Hong-Kong: City University of Hong-Kong. ISBN: 978-9629371890. 